\title{
ANALISANDO AS RELAÇÕES NA CADEIA DE SUPRIMENTOS ATRAVÉS DA TEORIA DOS CUSTOS DE TRANSAÇÃO
}

\author{
ANALYZING THE RELATIONS IN THE SUPPLY CHAIN THROUGH THE \\ TRANSACTION COSTS THEORY
}

\author{
Monize Sâmara Visentini ${ }^{1}$, Cleiciele Albuquerque Augusto ${ }^{2}$ \\ E José Paulo de SouzA ${ }^{3}$
}

Recebido em: 12/10/2011

Aprovado em: 23/02/2012

\section{RESUMO}

A Teoria dos Custos de Transação (TCT) pode contribuir na explicação do funcionamento e das relações da Cadeia de Suprimentos. Tendo em vista os aspectos convergentes dessas duas abordagens, este ensaio teórico objetiva compreender como a racionalidade limitada, o oportunismo e a relação interfirmas, aspectos presentes na TCT, podem influenciar na gestão da cadeia de suprimentos. Alguns indícios demonstram que tanto a racionalidade limitada quanto o oportunismo aumentam conforme se tem um acréscimo de complexidade e incerteza na transação. O compartilhamento da informação atua como fator fundamental na redução desses inconvenientes, contribuindo para que se consiga melhorar a relação interfirmas e minimizar os custos de transação. Também são evidenciados os aspectos que podem trazer vantagem competitiva às empresas participantes de uma cadeia de suprimentos, dentre eles, a adoção correta da estratégia de governança.

Palavras-chave: Teoria dos Custos de Transação; Cadeia de Suprimentos; Racionalidade Limitada; Oportunismo; Relação Interfirmas.

\section{Introdução}

A gestão da cadeia de suprimentos (Supply Chain Management) apresenta-se como uma área em rápida evolução, despertando o interesse do meio acadêmico e dos profissionais da área de administração. O fato da importância da gestão da cadeia de suprimentos ter aumentado ao longo dos últimos anos

\begin{abstract}
The Transaction Cost Theory (TCT) can contribute to explain the functioning and the relationship of the Supply Chain. Face of the converging aspects of these two approaches, the objective of this theoretical paper is understand how the bounded rationality, the opportunism, and the interfirm relationship, aspects presents in the TCT, can influence the supply chain management. Some evidences show that both, the bounded rationality and the opportunism increases, when there is an increase of complexity and uncertainty in the transaction. The information sharing acts as a key factor in reducing these problems, contributing to improve the interfirm relationship and minimize the transaction costs. We show also aspects that can bring competitive advantage to the participating companies in the supply chain, including the correct adoption of the governance strategy.
\end{abstract}

Keywords: Transaction Cost Theory; Supply Chain; Bounded Rationality; Opportunism; Interfirm Relationship.

se embasa na tentativa de alcançar vantagens competitivas no mercado, em situações de ambiente global cada vez mais dinâmico. Nesse contexto, o desenvolvimento de trocas cooperativas entre as firmas pertencentes à cadeia aponta-se como uma prática que pode dar suporte a esse desafio.

Ao se refletir sobre os elementos que permeiam a gestão da cadeia, per-

' Doutoranda pela Universidade Federal do Rio Grande do Sul, Brasil. E-mail:monize.s.visentini@gmail.com.

${ }^{2}$ Doutoranda pela Universidade Federal de Santa Catarina, Brasil. E-mail: cleicielealbuquerque@yahoo.com.br.

${ }^{3}$ Doutor em Engenharia de Produção pela Universidade Federal de Santa Catarina, Brasil. Pós-doutor em Administração pela Universidade de São Paulo.

E-mail: jpsouza@uem.br. 
cebe-se que a mesma está inserida em um ambiente de transações complexas. Nesse caso, a análise pela teoria neoclássica não se mostra adequada, uma vez que seu foco é voltado para a firma, o que a torna insuficiente para explicar a complexidade envolvida nas relações interfirmas (BARNEY; HESTERLY, 2004). Além disso, nessa teoria, não se observa a descrição do comportamento humano - dos gestores - como fator de influência na coordenação da cadeia. Ao se considerar a firma, as transações são tratadas como se ocorressem em um ambiente econômico sem conflitos, sendo que seu quadro teórico fornece artifícios escassos para analisar a gestão de cadeia de suprimentos.

Coase (1937) destaca que a teoria econômica neoclássica apresenta dificuldades para estabelecer com clareza suas suposições, e, para que se entenda o porquê da existência da firma, devese anteriormente conhecer as forças que regem a organização da atividade econômica. Portanto, o autor reconhece que existem custos de utilização do mecanismo de mercado, os custos de transação1, sendo que "uma firma tende a expandir até que os custos de organizar uma transação adicional dentro da própria empresa tornam-se iguais aos custos de realização da mesma transação por meio de troca no mercado aberto ou aos custos de organização em outra firma" (COASE, 1937, p. 395). A razão, então, para a existência da firma é baseada nos custos da realização de uma transação.

Ao complementar o trabalho de Coase e desenvolver um modelo mais completo sobre o custo de usar o mercado para gerenciar transações econômicas, Williamson apresenta a Teoria dos Custos de Transação (TCT). Williamson (1996) aprimorou a ideia dos custos de transação, sendo que esses incluem os custos de tempo e dinheiro para efetuar uma transação econômica, como a procura por informações; a escrita de contratos e a monitoração de seu cum- primento; a redução de conflitos quando não há acordos; e adaptações do acordo diante de imprevistos. Assim, a firma buscará minimizar os custos de transação, escolhendo a forma de organizar a atividade que for mais econômica.

Diante desse contexto, é válido notar que a visão econômica da existência dos custos de transação apresenta uma nova forma de explicar a organização das firmas e a forma como estas interagem ao longo de uma cadeia de suprimentos. Esses custos e a busca pela sua redução são de interesse da gestão da cadeia, pois podem gerar eficiência e vantagem competitiva. Caso contrário, relações adversas entre as firmas pertencentes à cadeia podem gerar aumento nos custos de transação. Essa explanação reforça a possibilidade de se compreender a gestão da cadeia de suprimentos a partir da análise dos custos de transação.

A consideração dos aspectos convergentes das duas abordagens traz à tona as seguintes questões de pesquisa: que aspectos comportamentais, sob o foco da teoria econômica, poderiam ser observados a fim de contribuir na relação interfirmas? Além disso, qual o tipo de relacionamento entre as firmas participantes da cadeia de suprimentos se torna mais adequado, ou, até mesmo, um fator estratégico, para o sucesso da gestão? Tais questionamentos, norteadores desta discussão, são originários da consideração de Hobbs (1996), segundo a qual, aspectos econômicos são importantes para o desenvolvimento de insights sobre como e por que diferentes modalidades da gestão da cadeia de suprimentos emergem, bem como para a compreensão das consequências desses acontecimentos para a eficiência e a competitividade da indústria.

Desse modo, a discussão apresentada neste trabalho foca em aspectos pontuais da TCT para ampliar a compreensão acerca da gestão da cadeia de suprimentos. Há diferentes pontos de vista quanto a essa relação, mas que 
foram, neste primeiro momento, sobrepostos pela escolha de foco nos aspectos comportamentais da TCT (racionalidade limitada e oportunismo) e da relação interfirmas, baseada na compreensão dos mecanismos de governança - ambos os aspectos considerados divisores de água entre a teoria de Williamson e Coase. Assim, o objetivo deste ensaio teórico é o de compreender como a racionalidade limitada, o oportunismo e a relação interfirmas, aspectos presentes na TCT, podem influenciar na gestão da cadeia de suprimentos.

A elaboração de uma discussão teórica acerca da gestão da cadeia de suprimentos, na visão de Croom, Romano e Giannakis (2000), contribui para o desenvolvimento científico dessa disciplina, que busca por avanços na representação de modelos teóricos para uma melhor compreensão dos seus fenômenos. Nesse aspecto, a justificativa deste estudo se sustenta na tentativa de compreender as vantagens da TCT para mostrar os mecanismos que podem explicar a organização e as formas de relacionamentos nas transações recorrentes entre firmas, as quais impactam na sua configuração interna.

Para atingir o objetivo proposto, este ensaio teórico apresenta duas seções, a partir desta introdução. A segunda realiza a discussão teórica em que se apresenta a TCT e a Gestão da Cadeia de Suprimentos, bem como os aspectos que convergem para a compreensão da relação de ambas. Na sequência, dentro da mesma seção, é discutida a racionalidade limitada dos agentes econômicos como influente na gestão da cadeia de suprimentos. O tópico seguinte enfoca o comportamento oportunista como fator de impacto nas decisões de gestão da cadeia de suprimentos. Finalmente, apresenta-se a relação interfirmas na gestão da cadeia de suprimentos. A última seção traz as considerações finais, seguida das referências utilizadas.

\section{Teoria dos custos de transação}

A TCT surgiu com Ronald Coase, que introduziu, em seu célebre artigo The nature of the firm, em 1937, uma nova perspectiva para o entendimento das estratégias empresariais ao mostrar que existem custos, além dos custos de produção, associados ao funcionamento dos mercados: os custos de transação (LANGLOIS; FOSS, 1997). Para Zylbersztajn (2009, p. 42), Coase introduziu uma mudança de paradigma na teoria econômica, implantando um novo marco teórico ao discutir "as razões explicativas para a existência da firma com base nos custos comparativos da organização interna e de produção via mercado, lançando as bases para o estudo das formas alternativas de organização das firmas contratuais".

Nas décadas de 1970 e 1980, a partir dos trabalhos realizados por Coase, Williamson (1985) impulsiona a questão dos custos de transação dentro da literatura econômica. Apresentando a transação como unidade de análise, a ECT tem como objetivo controlar os direitos de propriedade por meio do alinhamento de estruturas de governanças com atributos de transação. À medida que esse alinhamento ocorre, os custos de transação são minimizados. Conforme explica Demsetz (1968), logicamente a existência de custos de transação positivos não tem relevância direta para as ineficiências econômicas. No entanto, como acontece com qualquer custo, a questão que é relevante para a eficiência é se o custo é ou não apropriadamente economizado.

Os atributos que caracterizam uma transação, e cujo alinhamento deve ser levado em consideração na escolha de estruturas de governança, são três, segundo Williamson (1985): a frequência, a incerteza e a especificidade de ativos, sendo o último o mais decisivo pela sua importância estratégica. Conforme o autor, ainda se deve considerar a existência de pressupostos comporta- 
mentais, tais como a racionalidade limitada e a possibilidade de comportamento oportunista.

Segundo Williamson (1985), o atributo frequência diz respeito ao número de vezes que os agentes econômicos se encontram para realizar uma transação, considerando-se que, quanto maior a frequência, menores são os custos relacionados à coleta de informações e à elaboração de contratos, e maior a probabilidade de os parceiros desenvolverem reputação, limitando comportamentos oportunistas. Já a incerteza diz respeito às mudanças que surgem da complexidade do ambiente econômico, impossibilitando avaliações totalmente precisas. Considerase que quanto maior a incerteza, mais complexo torna-se o desenvolvimento de parcerias de longo prazo. Os ativos específicos, por sua vez, são ativos tangíveis ou intangíveis irrecuperáveis, no sentido de que não podem ser devolvidos para o mercado caso a relação de negócio original seja descontinuada, ou seja, não podem ser reempregáveis em outra transação sem perda de valor.

Além desses, a Teoria dos Custos de Transação parte de dois pressupostos comportamentais que a distinguem da abordagem tradicional: o oportunismo e a racionalidade limitada. Para Zylbersztajn (1995, p. 17), "o oportunismo parte de um princípio de jogo não cooperativo, onde a informação que um agente possa ter sobre a realidade não acessível a outro agente pode permitir que o primeiro desfrute de algum benefício do tipo monopolístico". De acordo com Klein, Crawford e Alchian (1978), a possibilidade de comportamento oportunista surge quando investimentos especializados são realizados e ocorre a geração de "quase-renda" e custos de saída. A "quase-renda" é definida, pelos autores, como o excesso do seu valor sobre o valor residual, ou seja, seu valor para um segundo melhor $\mathrm{uso}^{4}$. Conforme os autores, seguindo a orientação de Coase, o problema pode ser resolvido por dois caminhos: integração vertical ou contratação, uma vez que esses arranjos permitem um maior controle por parte da firma, evitando, assim, a captura de quase renda.

Da racionalidade limitada deriva a noção de incompletude contratual, ou seja, devido aos limites cognitivos que caracterizam os agentes, não é possível o estabelecimento de contratos que deem conta de todas as contingências futuras (WILLIAMSON, 1996). Conhecendo-se os os pressupostos comportamentais das transações e analisando-se os atributos presentes, é possível prever os arranjos institucionais que poderão ser adotados. Conforme Williamson (1985), esses arranjos podem se dar via mercado, hierarquia (integração vertical), ou contratos (as chamadas formas híbridas).

$\mathrm{Na}$ estrutura de governança via mercado, conforme Williamson (1985), o nível de especificidade de ativos é baixo, logo, os custos de transação são mínimos. Os agentes conhecem as características dos produtos transacionados, a incerteza e a frequência, nas transações, são mínimas, e normalmente não se cria reputação entre os agentes. A integração vertical, ou hierarquia, por sua vez, é motivada pelo alto nível de frequência, de incerteza e, principalmente, de especificidade de ativos, que pode atingir seis ramificações: locacional, temporal, humana, de marca, física e dedicada (WILLIAMSON, 1985). A integração vertical ocorre a partir da internalização das operações, subordinando-as à hierarquia e substituindo os custos de transação de mercado pelos custos de monitoramento interno.

Já os contratos, ou formas híbridas, de acordo com Ménard (2004) e Zylbersztajn (2005), referem-se aos arranjos de coordenação das transações que se diferem das estruturas via mercado e integração vertical. Estes podem se fazer necessários para garantir que não haja captura da "quase-renda" pelas partes envolvidas, ou seja, para garantir que não 
ocorra a perda ou expropriação do valor econômico do produto ou serviço transacionado. Segundo Ménard (2004), na medida em que as partes vão se conhecendo, aumenta o uso de mecanismos informais, tais como reputação, confiança, compartilhamento de informações e ajuda mútua, que são utilizados na coerção dos agentes. Na Figura 1, Ménard (2004) segmenta as formas híbridas em confiança, rede relacional, liderança e governança formal. As duas primeiras próximas da estrutura via mercado, e as duas últimas da estrutura hierárquica.

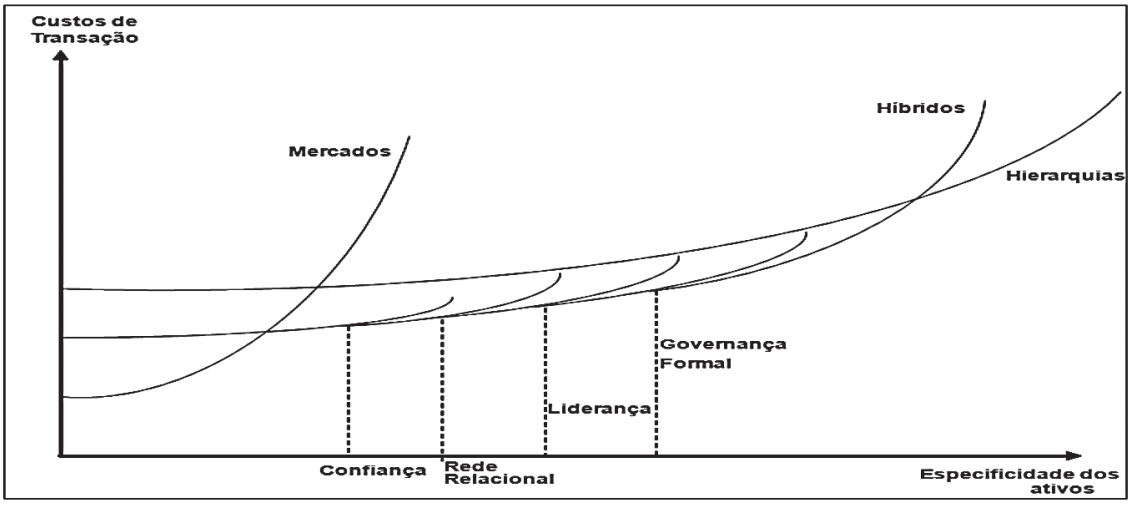

Figura 1 - Estruturas de governança

Fonte: Ménard (2004, p. 369).

De forma complementar, Demsetz (1995), apoiando-se na teoria da especialização, observa que a redução dos custos de transação gera a subdivisão das firmas, em que cada firma foca sua produção na parte de um todo. Nesse caso, não há uma substituição da firma pelo mercado ou uma substituição da coordenação pelos mecanismos de preço, mas sim um aumento no papel do gerenciamento na alocação de recursos pelas firmas, em função da desintegração vertical. Isso pode explicar a formação da cadeia de suprimentos e a sua necessidade de gestão.

\section{Gestão da cadeia de suprimentos}

Dado que as firmas se posicionam para se manterem competitivas, as mesmas enfrentam o desafio de transformar suas operações a partir de um ambiente empresarial estático para um dinâmico. Uma escolha óbvia para essa transformação é a operação da cadeia de suprimentos, devido ao seu impacto potencial sobre quase todos os aspectos das transações, o que envolve a totalidade da empresa (CHANDRA; GRABIS, 2007).

Uma cadeia de suprimentos consiste em um conjunto de instalações, fornecedores, consumidores, produtos e métodos de gestão de estoques, compras e distribuição. A cadeia é responsável pela ligação entre fornecedores e consumidores, iniciando com a produção da matéria prima e finalizando com a entrega do produto acabado ao consumidor final. Sabri e Beamon (2000) destacam que, em uma cadeia de suprimentos, o fluxo de mercadorias entre fornecedores e clientes passa por vários estágios, os quais são constituídos de diversas instalações.

O objetivo da cadeia de suprimento, de acordo com Chopra e Meindl (2003), é a maximização do valor global gerado, sendo esse valor a diferença entre o valor final do produto entregue ao cliente e o esforço que a cadeia de suprimentos realiza para atender ao seu 
pedido. Na maioria das cadeias de suprimento comerciais, o valor está ligado ao lucro destas, que pode ser considerado como a diferença entre a receita gerada pelo cliente e o custo total ao longo da cadeia.

Para coordenar de forma eficiente as ligações entre as partes que compõem a cadeia, conforme Lambert, Cooper e Pagh (1998), deve haver a integração de processos de negócioschave desde o usuário final até os fornecedores originais, os quais provêm produtos, serviços e informações capazes de adicionar valor para os consumidores e outros stakeholders. Esse processo é chamado de Gestão da Cadeia de Suprimentos ou Supply Chain Management. Na literatura, entretanto, encontram-se inconsistências no uso ou significado exato atribuído ao conceito "gestão da cadeia de suprimentos". Isso pode limitar aprofundamentos nas considerações acerca do tema, devido às incongruências geradas a partir de diferentes pontos de vista.

Definições como estratégia de compra integrada, integração de fornecedores, relações comprador-fornecedor, sincronização da cadeia de suprimento, alianças estratégicas de fornecimento, cadeia de valor agregado, cadeia produtiva, rede de suprimento são mencionadas como sinônimas à gestão da cadeia de suprimentos. Entretanto, deve-se observar que não são, em essência, termos que traduzem o mesmo significado dentro do campo das transações interfirmas.

A gestão da cadeia de suprimentos, conforme Harland (1996), pode ser utilizada para descrever quatro diferentes contextos: 1 . a cadeia de suprimentos interna, que integra funções do negócio, envolvidas no fluxo de materiais e informações; 2 . o gerenciamento de relacionamento entre a empresa e fornecedores imediatos; 3 . o gerenciamento de uma cadeia de negócios, incluindo todos os fornecedores e clientes; e 4. o gerenciamento de uma rede de negócios interconectados por diferentes processos e atividades na criação de valor para o cliente. Dadas essas possibilidades e as inconsistências encontradas na literatura acerca da definição do termo, neste ensaio, utiliza-se a definição abrangente dada por Ballou et al.(2000), que foca a gestão da cadeia produtiva, integrando todas as atividades associadas com a transformação e o fluxo de bens e serviços, desde as empresas fornecedoras de matéria-prima até o usuário final.

Uma boa gestão da cadeia de suprimentos pode trazer benefícios e ser o diferencial para as empresas. Caso contrário, há grandes riscos e prejuízos para as participantes da cadeia. Segundo Quental Júnior (2006), existem altos riscos, e não há opção em se correr ou não esses riscos se a empresa depende de parceiros para levar os produtos ao cliente final. Para buscar minimizar tais riscos, ao longo dos anos, empresas foram gerando alternativas e criando programas e estratégias, tais como o Just-in-Time, o VMI (Vendor Managed Inventory), a resposta rápida e a reposição contínua. Quental Junior (2006) salienta que esses programas têm em comum a troca de informações entre os parceiros, o que indica a necessidade de dados de qualidade e em tempo real na cadeia de suprimentos para permitir a integração e a busca pela gestão eficiente desta cadeia.

Sobre o gerenciamento das cadeias, Harland e Knight (2001) afirmam que as mesmas podem ser efetivamente gerenciadas, em contraste a outras visões que afirmam que as empresas participantes podem apenas lidar com a rede, mas não gerenciá-las ou controlá -las. Nesse sentido, os autores identificaram um espectro cujos extremos são "enfrentamentos reativos" e "controle da rede", ou seja, há diferentes tipos e variados graus de intervenção, que representam mais ou menos formas de pró-atividade na gestão da rede, o que depende do nível de relação entre as firmas e da troca de informações entre as 
participantes da cadeia.

Também sobre o gerenciamento da cadeia, Li et al. (2006) afirmam que existe uma relação positiva entre as práticas de gestão da cadeia de suprimentos, a vantagem competitiva e o desempenho organizacional. Para os autores, essas práticas de gestão são o conjunto de atividades empreendidas por uma organização para promover o gerenciamento efetivo de sua cadeia de suprimentos. As práticas específicas identificadas nesse estudo foram: parceria estratégica com fornecedores, relacionamento com o cliente, nível de compartilhamento da informação, qualidade da informação compartilhada e adiamento (prática de avançar uma ou mais operações ou atividades a um ponto adiante na cadeia de suprimentos). A partir dessas discussões, nas próximas seções, os fatores que permeiam a gestão da cadeia de suprimentos serão interconectados ao arcabouço conceitual da Teoria dos Custos de Transação.

\section{A teoria dos custos de transação e a gestão da cadeia de suprimentos: convergências}

As considerações acima expostas indicam que a TCT possibilita a análise da forma como as firmas se organizam na cadeia de suprimentos, a fim de atuarem no mercado de modo mais eficiente. Nesse sentido, a firma pode optar por adquirir, no mercado, todos os bens e serviços necessários ao seu processo produtivo ou internalizar todas as etapas desse processo, ou seja, a integrar as firmas verticalmente.

Percebe-se que, além de fornecer a liberdade para o gestor-empreendedor definir a relação da firma no mercado (relação interfirmas/ arranjos institucionais), a TCT apoia-se em dois pressupostos comportamentais essenciais acerca dos atores econômicos engajados em transações: a racionalidade limitada e o oportunismo. Esses aspectos favorecem a abordagem e compreensão da gestão da cadeia de suprimentos através da perspectiva da TCT.

Segundo Grover e Malhotra (2003), pouco se tem abordado a TCT na gestão de operações. Em particular, existe um número considerável de oportunidades dentro da disciplina de gestão de operações para avaliar a cadeia de suprimentos, muitas delas relacionadas com a perspectiva da TCT. Assim, este ensaio teórico foca, especificamente, na discussão da gestão da cadeia de suprimentos à luz dos pressupostos comportamentais básicos da TCT (racionalidade limitada e oportunismo), considerando a visão de relacionamento interfirmas.

4.1 Racionalidade limitada dos agentes econômicos: incerteza e complexidade como influentes na gestão da cadeia de suprimentos

A teoria econômica tradicional postula "homem econômico" aquele que, ao ser econômico, é também racional, sendo a ele creditado o mérito de possuir conhecimento sobre os aspectos relevantes do seu ambiente (SIMON, 1955). O modelo racionalista "puro" de decisão pressupõe que o gestor deveria e poderia explorar cada caminho que o leva a atingir seus objetivos, colher informações sobre custos e utilidade de cada um, comparar sistematicamente essas várias alternativas e escolher a opção mais eficaz. Esse modelo apresenta concepções totalmente seguras sobre como são as decisões e como estas devem ser tomadas.

A teoria econômica sobre o processo decisório afirma que aqueles que estão envolvidos nas transações econômicas são puramente racionais e que fazem as escolhas ótimas. Porém, no mercado real, essas exigências de juntar e processar informações são impraticáveis, não sendo disponível, a todo o momento, um rol completo e consistente de alternativas para serem escolhidas. O que há são simplificações da realida- 
de, que possibilitam que seja tomada a decisão, considerando os aspectos mais relevantes. Com vistas a essas limitações, Simon (1979) afirmou que o comportamento humano não é totalmente, mas sim intencionalmente racional, ressaltando a teoria da racionalidade limitada $^{6}$. É esse autor quem primeiramente aborda o relativismo e as limitações do processo de tomada de decisão, propondo a ideia do homem administrativo em contrapartida ao homem econômico, simplista e puramente racional.

A crítica ao homem econômico, oriunda de Simon (1979), é decorrente do fato de o comportamento real do ser humano não alcançar a racionalidade objetiva em sua totalidade. Isso porque a racionalidade requer um conhecimento completo e antecipado das consequências resultantes de cada opção, sendo que, na prática, o conhecimento dessas consequências é sempre fragmentado. Em uma transação econômica, por exemplo, as pessoas poderiam escrever contratos de ilimitada complexidade que especificariam todas as contingências possíveis, fato inviável. Assim, devido à racionalidade limitada, contratos complexos desaparecem diante da incerteza (BARNEY; HESTERLY, 2004). A consideração e a compreensão desse comportamento incidem sobre a gestão da cadeia de suprimentos, ao limitar a formalização das operações interfirmas, refletidas na elaboração dos contratos.

A TCT descreve a racionalidade limitada como um problema em condições de incerteza, pois a mesma dificulta a definição plena das categorias em torno de uma transação entre firmas, ocasionando um problema econômico. Nesse sentido, ao se observar a gestão da cadeia de suprimentos, não se tem a possibilidade de categorizar todas as contingências que devem ser incorporadas em um contrato, dando origem a custos de transação mais altos, que poderão ser minimizados através de uma escolha correta de relação interfirmas - os mecanismos de governança.

Assim, a racionalidade na análise da gestão da cadeia de suprimentos pode ser resumida em termos da absoluta impossibilidade de os gestores dominarem e conseguirem processar a totalidade das informações. Isso se torna necessário para a tomada de decisão adequada às situações negociais que estão impostas às firmas participantes do processo. As informações são custosas e, para minimizar esse custo, torna-se necessário o estabelecimento de mecanismos de coordenação e de estruturas de governança especiais. Nesse caso, devem considerar os atributos das transações e as características do complexo ambiente em que estão inseridas as firmas. Ao estabelecer esses mecanismos e estruturas, segundo Williamson (1985), os agentes devem considerar os custos de planejamento, adaptação e monitoramento das transações.

Na gestão da cadeia de suprimentos, portanto, quanto maior o grau de incerteza relacionado à transação entre as firmas, maior será o custo de transação. Isso ocorre, conforme Grover e Malhotra (2003), porque a racionalidade limitada dos indivíduos, em alguns casos, limita a capacidade de detalhar todas as condições da árvore de decisão ex-ante (relativo à transação). Esse fator incrementa os custos de transação, já que ocasiona a necessidade de especificar um contrato incompleto entre as partes, bem como os custos econômicos da gestão desse contrato. Sob condição de incerteza e complexidade, portanto, a racionalidade limitada força as partes atuantes na cadeia de suprimentos a incorrer a custos de transação associados com as negociações em curso sobre especificações de contrato e preços dos produtos transacionados.

Reconhece-se, assim, que as transações realizadas entre firmas que pertencem a uma cadeia produtiva são permeadas de complexidade e de incerteza - tanto econômicas quanto operacionais. Dada a limitação cognitiva, os 
agentes econômicos são incapazes de antecipadamente prever e estabelecer medidas corretivas para qualquer evento que possa ocorrer quando da realização de uma transação. Nesse sentido, as firmas atuantes em uma mesma cadeia de suprimentos devem considerar as dificuldades derivadas das suas condutas futuras e garantir que os compromissos sejam honrados dentro da continuidade da sua interação. A racionalidade limitada e o oportunismo dão origem aos custos de transação e devem ser avaliados e reduzidos cautelosamente pelos gestores integrantes da cadeia de suprimentos.

4.2 Comportamento oportunista como fator de impacto nas decisões de gestão da cadeia de suprimentos

O oportunismo é outro pressuposto comportamental da TCT que pode contribuir na análise da gestão da cadeia de suprimentos. Segundo Williamson (1975), a TCT leva em conta a busca do interesse próprio com dolo. Esse comportamento é permeado por mentira, roubo e trapaça, que geralmente se refere a "[...] uma revelação incompleta ou distorcida de informações, especificamente voltadas ao esforço de enganar, alterar, disfarçar, ofuscar, ou, de outra maneira confundir" (WILLIAMSON, 1985, p. 47) parceiros numa transação. Isso não implica, entretanto, que os atores econômicos sejam sempre oportunistas.

O oportunismo na gestão da cadeia de suprimentos pode apresentar um risco maior quando há um problema de negociação entre poucas firmas. $\mathrm{Na}$ existência, por exemplo, de um pequeno número de fornecedores disponíveis para um comprador, pode acontecer de algum fornecedor agir de forma oportunista para alterar os termos das relações de negócio em benefício próprio, como exigir um preço mais elevado do que o anteriormente acordado. Isso porque é possível existir um comportamento oportunista motivado pela circunstân- cia da transação, ressaltando, assim, a importância de se discutir essa conduta quando se analisa a gestão da cadeia de suprimentos.

Nesse sentido, Bello, Lohtia e Sangtani (2004) afirmam que a manutenção dos problemas relativos ao risco do oportunismo em contratos entre os parceiros comerciais inibe e motiva as firmas a evitar, preventivamente, potenciais investimentos improdutivos. Assim, a confiança entre as partes envolvidas não pode ser estabelecida simplesmente a partir da existência de um contrato: todo contrato implica riscos, devendo ser constantemente revisto pelas partes interessadas.

$\mathrm{Na}$ TCT, há o reconhecimento de que as trocas comerciais são caracterizadas por muitas informações, incompletas, imperfeitas ou assimétricas (HOBBS, 1996). A assimetria da informação, especificamente, surge quando há informação pública disponível para todos os participantes de uma transação, mas há também informação confidencial que está disponível apenas para agentes específicos, de modo que nem todos têm os mesmos níveis de informação. Uma indagação, a este ponto da discussão, refere-se à relação entre a assimetria informacional e a ação oportunista, ou seja, qual a relação visualizada entre esses conceitos e como essa relação pode interferir na gestão da cadeia de suprimentos?

Problemas informacionais podem, sim, levar a um comportamento oportunista na cadeia de suprimentos. Primeiro, pode haver um oportunismo ex-ante, no qual a informação está escondida antes da realização de uma transação. Akerlof (1970) caracteriza essa situação como situação adversa, ou seja, uma situação de assimetria informacional na qual o vendedor pode dispor de informações sobre defeitos em um produto antes da realização da transação e não disponibilizá-la ao potencial comprador. Como resultado, o vendedor pode agir de forma oportunis- 
ta ao não revelar esses defeitos antes da operação. Informações ocultas podem levar à seleção adversa e a problemas de comportamento oportunista. Nesse caso, o direito contratual pode atenuar o problema da seleção adversa, fornecendo uma maior proteção para o comprador.

Um segundo caso, conforme Akerlof (1970), é o oportunismo ex -post, que acontece após uma transação, devido a ações ocultas dos indivíduos ou das firmas nela atuantes. Essas partes podem ter incentivos para agir de forma oportunista a fim de aumentar o seu bem-estar econômico, visto que suas ações não são diretamente observáveis por outros participantes da cadeia. Em contrapartida, quando há o compartilhamento de informação que vai além de dados sobre transações de compra e venda, incluindo aspectos estratégicos orientados ao planejamento conjunto, permite-se que as empresas participantes da cadeia façam o que é certo de maneira mais rápida e eficiente (BOWERSOX; CLOSS, 2001). Essas situações opostas demonstram que o oportunismo pode estar presente na cadeia de suprimentos através do compartilhamento da informação entre as firmas participantes, e ressalta a importância da elaboração e do monitoramento de cláusulas contratuais específicas a cada transação.

A gestão da cadeia de suprimentos sob a ótica da TCT, por meio da elaboração de contratos que minimizam o risco do oportunismo, pode gerar custos de transação, dado a necessidade de monitorar o comportamento, salvaguardar ativos e certificar que a outra parte não tem um comportamento oportunista. A presença do oportunismo em algumas partes da cadeia incita vigilância constante, aumentando os custos de transação. No entanto, em médio prazo, quando um padrão é estabelecido e mecanismos de salvaguarda são determinados, esses custos tendem a diminuir e, em alguns casos, tornarem-se irrisórios (BARZEL, 2005).
As discussões apresentadas levam à consideração da relação entre o comportamento oportunista dos agentes da cadeia de suprimentos e a respectiva tomada de decisão acerca do processo. Salienta-se que o desempenho da cadeia depende criticamente da forma como seus membros coordenam as respectivas decisões. Nesse caso, é difícil imaginar que, sem coordenação entre os agentes, haja alguma forma de compartilhamento de informações. Desse modo, tanto a racionalidade limitada quanto o oportunismo influenciam as decisões que permeiam a gestão da cadeia de suprimentos, não podendo ser desconsiderados quando da realização das transações interfirmas.

Em suma, os pressupostos da racionalidade limitada e do oportunismo são facetas distintas da TCT e, juntos, dão origem a custos de transação que incidem sobre as firmas participantes da cadeia de suprimentos. Para organizar as operações e buscar a minimização desses custos, os gestores devem utilizar dos mecanismos de governança adequados, alinhados aos atributos de transação e pressupostos comportamentais. Como as partes transacionam por meio de contratos, é necessário que estes apresentem salvaguardas contratuais capazes de minimizar os efeitos negativos resultantes da presença desses fatores.

4.3 A relação interfirmas na gestão da cadeia de suprimentos

Na TCT, os mecanismos de governança, segundo Williamson (1991), são distinguidos com base na medida em que os atores coordenam ou controlam as várias fases do processo produtivo. Nesse sentido, a decisão acerca da governança da TCT é direta. Os atores econômicos irão escolher a estrutura de governança que "reduza possíveis problemas transacionais, criados pela racionalidade limitada, por um lado, e pela ameaça do oportunismo por 
outro, a um menor custo" (BARNEY; HESTERLY, 2004, p. 136). A governança das transações econômicas é onerosa, pois, na realização de transações no mercado, há riscos para a empresa. Os contratos são incompletos em sua natureza, e os agentes humanos apresentam racionalidade limitada e são levados ao oportunismo pela busca do seu próprio interesse. Esses fatores influem na escolha do tipo de estrutura de governança a adotar e nos custos que dela incorrem.

Sob o foco da TCT, segundo Hobbs (1996), os determinantes dos mecanismos de governança a adotar são a natureza e o nível dos custos de transação, pois uma mudança nos custos de transação decorrentes do intercâmbio de um produto pode levar a uma mudança em toda a gestão da cadeia de suprimentos. Na gestão da cadeia de suprimentos, a escolha da estrutura de governança é mais voltada para o continuum entre o mercado e a forma híbrida (MARTINEZ e ZERING, 2004 apud WENER et al., 2010), pois as firmas dependem dos preços e da concorrência para a coordenação das operações, bem como da formalização dos processos interfirmas. Isso porque, na cadeia de suprimentos, diferentes agentes são partes autônomas, e, às vezes, oportunistas, sendo que a autonomia das partes faz com que os mecanismos de governança presentes entre o mercado e as formas híbridas sejam mais eficientes do que a hierarquia, na qual os produtos se movem entre as diversas fases da cadeia de produção-processamento-distribuição, como resultado de ordens internas de cada gestor e não da direção dos preços. A ameaça de os compradores mudarem para outros fornecedores da cadeia incentiva que se opte por mecanismos relacionados às mudanças de preço, ou se estabeleçam contratos de longo prazo, pautados no formalismo e na busca pela minimização do oportunismo.

Mais especificamente, quando um grupo de firmas mantém relações contínuas, como ocorre entre as empre- sas que participam de uma cadeia de suprimentos, a forma híbrida apresenta mais incentivos e capacidade de adaptação ao processo, ampliando o controle administrativo (WILLIAMSON, 1991). Menard (2004) afirma que o foco fundamental das firmas híbridas é o compartilhamento de recursos e a coordenação de decisões a fim de gerar rendimentos. Entretanto, isso também pode ser alvo de conflitos: a distribuição de rendimentos envolve escolhas arbitrárias, que podem desestabilizar um acordo. Em geral, a visão que as firmas têm sobre seus fornecedores se baseia no conceito de oportunismo utilizado na TCT. Assim, os tipos de contratos e os mecanismos de governança que regem as relações de suprimento também se apoiam nessa teoria.

Anderson e Dekker (2009) afirmam que as formas híbridas de organização também oferecem incentivos financeiros mais altos que a governança de mercado. Uma variedade de formas híbridas é utilizada em colaborações comprador/fornecedor, incluindo os acordos contratuais, participações minoritárias e joint ventures, e cada um está associado a diferentes custos e oferece distintos graus de controle sobre a atividade colaborativa. A hipótese acerca da estratégia colaborativa, segundo Zawislak (2004), é que a cooperação interfirmas acontece porque os custos de transação de determinar o preço em um mercado competitivo seriam muito maiores que os custos de transação de estabelecer um contrato de cooperação.

A relação interfirmas, proporcionada pela cadeia de suprimentos, condiciona a firma a fazer face às exigências do ambiente institucional, a partir do monitoramento de eventuais mudanças e comportamentos dos agentes econômicos envolvidos na transação. Ao se aumentar a incerteza, tem-se um incremento considerável nos custos de transação da forma híbrida, bem como no aumento de atitudes oportunistas. Dadas essas mudanças, há diferentes tipos 
de contratos que podem ser realizados a fim de minimizar os custos e os riscos de uma parceria.

Hobbs (1996) destaca três grandes grupos de contratos: a) os contratos de especificação do mercado representam um acordo feito pelo comprador para oferecer um mercado para a produção de um vendedor. O vendedor transfere alguns dos riscos e decisões sobre quando o produto é vendido e como ele é comercializado para o comprador. $\mathrm{O}$ controle sobre o processo de produção, entretanto, permanece com o vendedor; b) os contratos de gestão da produção dão maior controle para o comprador do que um contrato de especificação de mercado. O comprador participa da gestão da produção através do controle dos processos produtivos e especifica a utilização dos insumos; c) nos contratos de fornecimento de recursos, um controle ainda maior recai sobre o comprador, que fornece uma saída de mercado para o produto, supervisiona sua produção e fornece insumos essenciais.

Ao se considerarem as relações envolvendo as cadeias produtivas, pode se identificar etapas sucessivas de criação de valor e possibilidades de captura notadamente nas relações verticais. Em com- plemento, Lazzarini, Chaddad e Cook (2001), observam que, nessas relações entre os segmentos, as variáveis relacionadas à coordenação horizontal também exercem influência. Esse tipo de coordenação é denominada pelos autores de $\mathrm{Ne}$ twork Analysis (NA) e considera as relações entre firmas de um mesmo grupo ou pertencentes a uma indústria. No campo dessas relações, três principais fontes de valor da Rede de Análises estão mais relacionadas aos aspectos humanos, como: estrutura social, relacionada ao papel do indivíduo e suas relações interpessoais; aprendizagem individual ou gerada por intermédio de troca; externalidades das redes ${ }^{5}$.

A consideração das cadeias de suprimentos e network é incorporada pelos estudos, denominados por Lazzarini, Chaddad e Cook (2001), de netchain. Por netchain, consideramse as relações horizontais entre firmas (network), que são sequencialmente arranjadas em relações verticais (Supply chain). Diante disso, três tipos de interdependência, relacionadas ao network e netchain, e formas de coordenação são identificadas, sendo elas a conjunta, sequencial e recíproca (Figura 2).

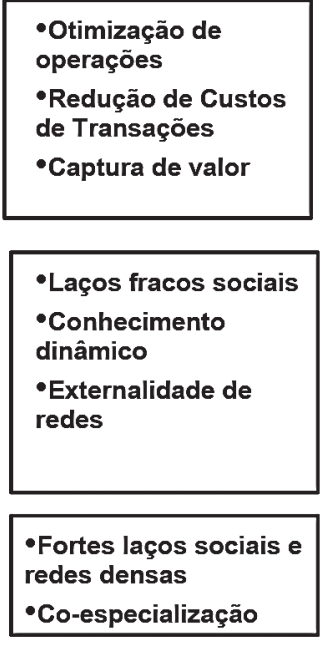

Fontes de Valor

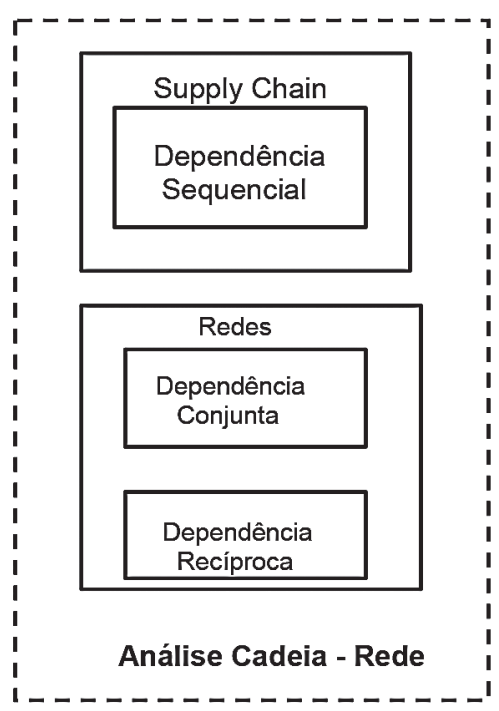

Figura 2 - Perspectivas da análise de cadeia: rede Fonte: Lazzarini, Chaddad e Cook (2001)

\section{Planos \\ Gerenciais}

Processos

Padronizados

Ajustes

Mútuos

Mecanismos de Coordenação 
Com relação aos três tipos de interdependência, Lazzarini, Chaddad e Cook (2001) observam que a dependência sequencial está associada às análises da cadeia de suprimentos e às outras duas redes de análises. Isso ocorre pois a dependência sequencial envolve relacionamento direto entre agentes ordenados sequencialmente, formando a cadeia de suprimentos (LAZZARINI; CHADDAD; COOK, 2001, p. 6). Para os autores, as ações são orientadas para otimizar os processos produtivos seqüenciais e as operações. Quanto aos mecanismos de governança, esses são direcionados à redução de custos de transação e de apropriação dos direitos de propriedade em estágios para cima e para baixo da cadeia.

No que se refere à interdependência conjunta e recíproca, verifica-se que as fontes de valor de cada uma estão associadas a algumas fontes da network. A interdependência conjunta está presente em fracos acordos sociais e papéis estruturais, pois o relacionamento entre os agentes é mais escasso e indireto. Tal fato faz com que o conhecimento seja diversificado e a troca entre os agentes possa ser direta ou indireta. No caso da dependência recíproca, os agentes têm uma dependência mútua, tanto nas escolhas como as ações de cada um deles. Nesse caso, o relacionamento entre os agentes exige fortes acordos e densas networks, sendo que o conhecimento de um está fortemente dependente do conhecimento do outro, ou seja, o conhecimento é coespecializado.

Quanto aos mecanismos de coordenação, os planos gerenciais dizem respeito à dependência sequencial, pois requerem o estabelecimento de uma programação para que as unidades interdependentes tenham suas ações gerenciadas (LAZZARINI; CHADDAD; COOK, 2001). Com relação aos outros dois tipos de mecanismos de coordenação, os planos padronizados se associam à dependência conjunta, visando a definir regras padronizadas e meca- nismos compartilhados para transações complexas. Já os planos mútuos se referem à dependência recíproca, visto que, requerem a troca de informações e o feedback entre as partes envolvidas. Conforme observa Saes (2009, p. 87), como "[...] o problema não é trivial pressupõe-se algum mecanismo de consenso, negociação entre as partes e ajuste mútuo".

No intuito de minimizar os custos de transação, as firmas devem escolher adequadamente os mecanismos de governança a adotar para realizar as transações interfirmas, bem como analisar e decidir sobre a melhor opção contratual. Nesse ponto, recai novamente a importância de se observar a racionalidade limitada e buscar o decréscimo do oportunismo, pois, assim, têm-se condições de procurar adotar o tipo de estrutura de governança mais adequada e elaborar contratos e parcerias que contribuam para o desempenho de todas as firmas participantes da cadeia. Entretanto, salienta-se que sempre haverá o interesse próprio de cada firma frente ao mercado, sendo que não se tem condições de verificar o relacionamento da cadeia de suprimentos apenas com base na cooperação e na confiança interfirmas.

\section{Considerações finais}

O foco deste trabalho foi analisar a gestão da cadeia de suprimentos sob a ótica da TCT, especificamente, por intermédio dos conceitos comportamentais de racionalidade limitada e oportunismo, assim como identificar a relação interfirmas, tendo como ponto de partida os mecanismos de governança. Esclarece-se que o mesmo não teve a pretensão de abarcar uma análise exaustiva do tema, mas serviu como busca coerente e teoricamente embasada de se compreender como os aspectos comportamentais dos gestores podem influenciar na gestão da cadeia de suprimentos, buscando proporcionar contribuições teóricas para a consoli- 
dação da TCT como uma base teórica no tratamento da gestão da cadeia de suprimentos. Tal abordagem justifica-se na medida em que a TCT apresenta um conjunto de pressupostos teóricos importantes na análise de relações interfirmas, que compõem, necessariamente, uma cadeia de suprimentos.

Uma das indagações iniciais era a de como esses aspectos poderiam ser observados a fim de contribuir na relação interfirmas na cadeia de suprimentos. Como resposta, observou-se que tanto a racionalidade quanto o oportunismo tendem a aumentar conforme se tem um acréscimo de complexidade e incerteza na transação. Assim, o compartilhamento da informação atua como aspecto fundamental na redução desses fatores, contribuindo para que se consiga melhorar a relação interfirmas e minimizar os custos de transação. Ao se organizar uma cadeia na qual os agentes mantém relações cooperativas de troca de informações, há ganhos tanto na tomada de decisão quanto no planejamento das ações futuras, visto que se pode escolher por alternativas mais precisas e justas, com a participação de agentes com conhecimentos diversos. Isso porque a assimetria de informação, ou até mesmo a falta de informação, aumenta a complexidade da decisão na cadeia de suprimentos, prejudicando o seu desempenho global.

Entretanto, a troca de informações poderá existir quando se conseguir eliminar, pelo menos em parte, a possibilidade de comportamento oportunista dos participantes da cadeia de suprimentos. A dificuldade se estabelece na medida em que cada agente busca, na maioria das vezes, por melhores resultados individuais. Por outro lado, há a possibilidade de se desenvolver um relacionamento de trocas cooperativas entre as firmas, que podem estar pautadas em uma maior transparência nas transações e no compartilhamento de informações ex-ante e ex-post.

Outro aspecto que pode trazer vantagem competitiva às empresas participantes de uma cadeia de suprimentos é a adoção correta da estratégia de governança. Ao se acertar nessa escolha, incorre-se em uma redução nos custos de transação, contribuindo na diminuição do ônus total da cadeia. Conforme observado, o estudo e a compreensão das estruturas de governança tornamse centrais para a gestão da cadeia de suprimentos. Pode se inferir que, nessa gestão, as estruturas de governança mais apropriadas são as formas híbridas ou os contratos. Esses tipos de estruturas indicam uma maior formalização dos processos interfirmas e a consequente minimização do oportunismo e dos riscos envolvidos. Entretanto, indiferentemente do tipo de contrato realizado entre os participantes da cadeia de suprimentos, estes sempre podem apresentar o inconveniente de serem por tempo limitado e necessitarem, periodicamente, de atualização e renovação, aumentando os custos das transações.

Percebeu-se que a consideração da TCT para entendimento dos mecanismos relacionais e organizacionais na supply chain oferece importantes contribuições. Dentre estas, podem se destacar os mecanismos que viabilizam a sua gestão coordenada, por intermédio do alinhamento entre atributos e estrutura. Além disso, a consideração dos pressupostos teóricos apresentados explica como se organizar em função de diferentes níveis de interdependência; como distribuir e minimizar incertezas nas relações entre empresas, e como planejar dada a dependência sequencial estabelecida, de forma garantir direito de propriedade e/ou minimização de apropriação de renda.

Como limitação da presente investigação, salienta-se que, ao abordar a Teoria dos Custos de Transação, tem-se uma visão da gestão da cadeia de suprimentos fortemente calcada em redução de custos, não se considerando outras capacidades necessárias para as organizações, como o conhecimen- 
to. Outra limitação é que a TCT tende a subestimar o papel das forças sociais e culturais na atividade econômica ao adotar uma visão calculista das pessoas. Essas questões podem ser sanadas com estudos futuros, que abordem aspectos sociais e culturais existentes na relação interfirmas.

Mesmo reconhecendo essas limitações, este trabalho buscou analisar a gestão da cadeia de suprimentos sob o foco da TCT, pois, a partir da literatura existente, esta tem sido operacionalizada com êxito e empiricamente testada, diferente de outras teorias econômicas. Além disso, ao considerar os aspectos comportamentais e inter-relacionais abarcados pela TCT, está se fornecendo uma nova perspectiva da gestão da cadeia de suprimentos. Outros aspectos dessa teoria podem ser analisados, futuramente, a fim de complementar a análise aqui realizada.

\section{Notas:}

O termo "Custos de Transação" foi disseminado por Williamson, em Economics and organization: a primer (1996), ao retomar os estudos de Coase. Embora Coase tivesse sugerido a existência desses custos, não os havia denominado (SWEDBERG, 2003).

${ }^{4}$ The quase-rent value of the asset is the excess of its value over its salvage value, that is, its value in its next best use to another renter (Klein, Crawford e Alchian, 1978, P. 298).

${ }^{5}$ A concepção da racionalidade limitada, proposta por Simon, foi merecedora do Prêmio Nobel em 1978.

${ }^{6}$ Neste trabalho, é utilizada a definição de Farina (1997, p. 115) para externalidades das redes positivas ou negativas, como aquelas que "[...] ocorrem sempre que o cálculo privado diferir do cálculo social da produção ou investimento".

\section{Referências}

AKERLOF, G. A. The market for 'lemons': qualitative uncertainty and the market mechanism. Quarterly Journal of Economics, v. 84, p. 488500, 1970.

ANDERSON, S. W.; DEKKER, H. C. Strategic Cost Management in Supply Chains, Part 1: Structural Cost Management. Accounting Horizons, v. 23, n. 2, p. 201-220, 2009.

BALLOU, R. H.; GILBERT, S. M.; MUKHERJEE, A. New Managerial Challenges from Supply Chain Opportunities. Industrial Marketing Management, v. 29, p.7-18, 2000.

BARNEY, J. B.; HESTERLY, W. Economia das organizações: entendendo a relação entre organizações e a análise econômica. In: Nota técnica In: CLEGG, S.; HARDY, C; NORD, D. (Orgs.) Handbook de estudos organizacionais. São Paulo: Atlas, 2004. v.3, p.131-179.

BARZEL, Yoram. Organizational Forms and Measurement Costs. Journal of Institutional and Theoretical Economics, v. 161, p. 357-373, 2005.

BELLO, D. C.; LOHTIA, R., SANGTANI, V. An institutional analysis of supply chain innovations in global marketing channels. Industrial Marketing Management, v. 33, p. 5764, 2004.

BOWERSOX, D. J.; CLOSS, D. J. Logística Empresarial: O Processo de Integração da Cadeia de Suprimento. São Paulo: Editora Atlas, 2001. 
CHANDRA, C.; GRABIS, J. Supply Chain Configuration: Concepts, Solutions and Applications. New York: Springer Science, 2007.

CHOPRA, S.; MEINDL, P. Gerenciamento da cadeia de suprimentos. 1. ed. São Paulo: Prentice Hall, 2003.

COASE, R. H. The nature of the firm. Economica, v.4, 16, p.386-405, 1937. CROOM, S.; ROMANO, P.; GIANNAKIS, M. Supply chain management: an analytical framework for critical literature review. European Journal of Purchasing and Supply Management, v. 6, p. 67-83, 2000.

DEMSETZ, Harold. The cost of transacting. The Quarterly Journal of Economics, v. 82, n. 1, p. 33-53, 1968.

The economics of the business firm: Seven critical commentaries. Cambridge University Press; Cambridge and New York, 1995.

GROVER, V.; MALHOTRA, M. K. Transaction cost framework in operations and supply chain management research: theory and measurement. Journal of Operations Management, v.21, p. 457-473, 2003.

HARLAND, C. M. Supply Chain Management: Relationships, Chains and Networks, British Journal of Management, v.7, Special Issue, 1996.

HARLAND, C. M.; KNIGHT, L. Supply Network Strategy: Role and Competence Requirements. International Journal of Operations \& Production Management, v. 21, n. 4, 2001.
HOBBS, J. E. A transaction cost approach to supply chain management. Supply Chain Management, v.1, n. 2, p. 15-27, 1996.

\section{KLEIN, B.; CRAWFORD, R.; ALCHIAN, A. Vertical integration, appropriable rents, and the competitive contracting process. Journal of Law, Economics and Organization, v. 21, p. 297, 1978.}

LAMBERT, D. M., COOPER, M. C.; PAGH, J. D. Supply Chain Management: Implementation Issues and Research Opportunities. The International Journal of Logistics Management. v. 9, n. 2, 1998, p. 1-19.

LAZZARINI, S., CHADDAD, F. COOK, M. Integrating Supply Chain and Network Analyses: The Study of Netchains. Journal on Chain \& Network Science, 2001, n. 1.

LI, S. et al. The impact of supply chain management practices on competitive advantage and organizational performance. Omega. V. 34, p. 107124, 2006.

MENARD, C. The Economics of Hybrid Organization. Journal of Institutional and Theoretical Economics. JITE 160, p. 345-376, 2004.

QUENTAL JÚNIOR, Antonio, J. J. Adoção e Implantação de RFID, Uma Visão Gerencial da Cadeia de Suprimentos. 2006. 155 p. Monografia (Master in Business Information Systems -MBIS). Programa de PósGraduação MBIS, Departamento de Computação, PUCSP, São Paulo, 2006. 
SABRI, E. H.; BEAMON, B. M. Amultiobjective approach to simultaneous strategic and operational planning in supply chain design. Omega, v. 28, p. 581-598, 2000.

SAES, M. S. M. Estratégias de diferenciação e apropriação da quaserenda na agricultura: a produção de pequena escala. São Paulo: FAPESP, 2009.

SIMON, H. A. A Behavioral Model of Rational Choice. The Quarterly Journal of Economics, v. 69, n. 1, p. 99-118, 1955.

\section{Comportamento administra-}

tivo: estudo dos processos decisórios nas organizações administrativas. 3. ed. Rio de Janeiro: Fundação Getulio Vargas, 1979.

SWEDBERG, R. Economic versus sociological approaches to organization theory. In: TSOUKAS, H.; KNUDSEN, C. (Eds). The Oxford handbook of organization theory. Oxford: Oxford University Press, 2003.

WILLIAMSON, O. E. Market and Hierarchies: Analysis and Antitrust Implications. New York: The Free Press, 1975.

Comparative economic organization: The analysis of discrete structural alternatives. Administrative Science Quarterly, v. 36, p. 269-296, 1991.

Economics and organization:

a primer. California Management Review, v.38, n.2, p.131-146, 1996. of capitalism: firms, markets, relational contracting. New York: The Free Press, 1985.

ZAWISLAK, P. In: Nota técnica In: CLEGG, S.; HARDY, C; NORD, D. (Orgs.) Handbook de estudos organizacionais. São Paulo: Atlas, 2004. v.3, p.180-185.

ZYLBERSZTAJN, D. A estrutura de governança e coordenação do agribusiness: uma aplicação da nova economia das instituições. 1995. 238 p. Tese (Livre-Docência) Faculdade de Economia, Administração e Contabilidade, Universidade de São Paulo, São Paulo, 1995.

ZYLBERSZTAJN, D. Measurement costs and governance: bridging perspectives of transaction cost economics. In: International Society for the New Institutional Economics ISNIE, Barcelona-Espanha, 2005.

ZYLBERSZTAJN, D. Papel dos contraltos na coordenação agroindustrial: um olhar além dos mercados. In: SOUZA, José Paulo de; PRADO, Ivanor Nunes do. Cadeias produtivas: estudos sobre competitividade e coordenação. 2. Ed. Maringá: EDUEM, 2009. 
